Check for updates

Cite this: RSC Adv., 2017, 7, 34482

Received 30th April 2017

Accepted 3rd July 2017

DOI: $10.1039 / \mathrm{c} 7 \mathrm{ra04852a}$

rsc.li/rsc-advances

\title{
Solution combustion synthesis and enhanced gas sensing properties of porous $\mathrm{In}_{2} \mathrm{O}_{3} / \mathrm{ZnO}$ heterostructures $\uparrow$
}

\author{
Xinwei Zou, (D)* Xiaoyan Yan, Guomin Li, Yuming Tian, Mingang Zhang \\ and Liping Liang
}

Self-assembled porous $\mathrm{I}_{2} \mathrm{O}_{3} / \mathrm{ZnO}$ heterostructures were prepared by a low temperature solution combustion synthesis method, and characterized using X-ray diffraction (XRD), scanning electron microscopy (SEM) and high resolution transmission electron microscopy (HRTEM). The results indicate that the as-synthesized porous $\ln _{2} \mathrm{O}_{3} / \mathrm{ZnO}$ heterostructures were constructed from a large number of $\mathrm{In}_{2} \mathrm{O}_{3}$ and $\mathrm{ZnO}$ nanoparticles and showed high gas sensing performance toward $\mathrm{Cl}_{2}$. Compared with pure $\mathrm{ZnO}$ and other heterostructure sensors, the porous $\ln _{2} \mathrm{O}_{3} / \mathrm{ZnO}$ heterostructures with an appropriate molar ratio of $\mathrm{In}_{2} \mathrm{O}_{3}: \mathrm{ZnO}$ exhibited highly enhanced gas sensing performances toward $\mathrm{Cl}_{2}$. An extremely high sensitivity of 6610 could be reached when exposed to $50 \mathrm{ppm} \mathrm{Cl}_{2}$ at $370{ }^{\circ} \mathrm{C}$; also, $\mathrm{In}_{2} \mathrm{O}_{3} / \mathrm{ZnO}$ heterostructures showed high selectivity toward $\mathrm{Cl}_{2}$. Furthermore, the gas sensing mechanism was discussed.

\section{Introduction}

Chlorine $\left(\mathrm{Cl}_{2}\right)$ is widely used in the chemical industry, but it is toxic. Exposure to chlorine will result in injury and disease. Properly installed, reliable gas detection can help prevent chlorine-related injury or death. Therefore, several sensing technologies have been reported for detection of $\mathrm{Cl}_{2}$, such as conductivity-type gas sensors using metal-oxides, ${ }^{1-4}$ gas chromatography, ${ }^{5}$ electrochemical sensors ${ }^{6}$ and chemical detecting tubes. ${ }^{7}$ As for gas chromatography and the chemical detecting tubes, the detecting process is very complicated. Electrochemical sensors can not detect dilute chlorine gas. Metal oxides and complex metal oxides are promising chlorine gas sensors due to their outstanding features including low cost, simple fabrication, good selectivity and high sensitivity..$^{8-10}$ However, the metal oxide gas sensors still have several unsolved problems such as slow response and long recovery time, which limit their commercial applications. For example, Tamaki's group has prepared $\mathrm{In}_{2} \mathrm{O}_{3}$ thin film chlorine gas sensors showing extremely high sensitivity to dilute $\mathrm{Cl}_{2}$ gas of $0.2-$ $5 \mathrm{ppm}$, while the recovery time is in the range of $1-15 \mathrm{~min} .{ }^{11} \mathrm{In}$ addition, a $\mathrm{WO}_{3}$ gas sensor for $\mathrm{Cl}_{2}$ also has similar disadvantages of slow response and long recovery time. ${ }^{2}$

School of Materials Science and Engineering, Taiyuan University of Science and Technology, Taiyuan 030024, P. R. China. E-mail: moodland@163.com; Tel: +86 3512161126

$\dagger$ Electronic supplementary information (ESI) available. See DOI: 10.1039/c7ra04852a
Gas sensing performance can be further enhanced by the appropriate integration of two different kinds of semiconductor oxides due to the strong interactions between the closely packed nano-units in the composites. ${ }^{12-14}$ Solution combustion synthesis SCS is an excellent method which is simple, high-efficiency and low-cost, and does not require high-temperature furnaces and complicated set-ups. ${ }^{15}$ Moreover, the products prepared by SCS tend to possess good crystallinity, small crystallite size, mesoporous nature and high surface area. ${ }^{16}$ Herein, the porous $\operatorname{~}_{2} \mathrm{O}_{3} /$ $\mathrm{ZnO}$ heterostructures have been prepared by the simple and lowcost SCS method, also the sensors based on the porous heterostructures show tremendously high sensitivity and fast response and recovery gas sensing properties toward $\mathrm{Cl}_{2}$ gas.

\section{Experiment}

All the chemical reagents such as zinc nitrate hexahydrate $\left(\mathrm{Zn}\left(\mathrm{NO}_{3}\right)_{2} \cdot 6 \mathrm{H}_{2} \mathrm{O}\right)$, oxalic acid dihydrate $\left(\mathrm{C}_{2} \mathrm{H}_{2} \mathrm{O}_{4} \cdot 2 \mathrm{H}_{2} \mathrm{O}\right)$, indium nitrate pentahydrate $\left(\mathrm{In}\left(\mathrm{NO}_{3}\right)_{3} \cdot 5 \mathrm{H}_{2} \mathrm{O}\right)$ used in the experiments are of analytical reagent (AR) grade without further purification. The typical synthesis procedure for the porous $\operatorname{In}_{2} \mathrm{O}_{3} / \mathrm{ZnO}$ heterostructures is as follow. First, a mixture aqueous solution containing stoichiometric amounts of zinc/indium nitrate and oxalic acid was stirred for about $30 \mathrm{~min}$ in order to make it transform into a uniform colloidal solution. Then, the colloidal solution was transferred to a pyrex dish. Next, the dish was introduced into a muffle furnace which has been preheated to $450{ }^{\circ} \mathrm{C}$ for $5 \mathrm{~min}$. In this situation the solution was heated rapidly and the following redox reactions could occur. 


$$
\begin{aligned}
& \mathrm{Zn}\left(\mathrm{NO}_{3}\right)_{2} \text { (aq.) }+ 5 \mathrm{C}_{2} \mathrm{H}_{2} \mathrm{O}_{4} \text { (aq.) } \stackrel{\Delta}{\longrightarrow} \\
& \mathrm{ZnO}(\mathrm{s})+\mathrm{N}_{2}(\mathrm{~g})+10 \mathrm{CO}_{2}(\mathrm{~g})+5 \mathrm{H}_{2} \mathrm{O}(\mathrm{g})
\end{aligned}
$$

$$
\begin{aligned}
2 \operatorname{In}\left(\mathrm{NO}_{3}\right)_{3}(\text { aq. })+15 \mathrm{C}_{2} \mathrm{H}_{2} \mathrm{O}_{4}(\text { aq. }) \stackrel{\Delta}{\longrightarrow} \\
\operatorname{In}_{2} \mathrm{O}_{3}(\mathrm{~s})+6 \mathrm{~N}_{2}(\mathrm{~g})+30 \mathrm{CO}_{2}(\mathrm{~g})+15 \mathrm{H}_{2} \mathrm{O}(\mathrm{g})
\end{aligned}
$$

During the reaction process, $\mathrm{Zn}\left(\mathrm{NO}_{3}\right)_{2}$ and $\mathrm{In}\left(\mathrm{NO}_{3}\right)_{3}$ acted as oxidants and $\mathrm{C}_{2} \mathrm{H}_{2} \mathrm{O}_{4}$ acted as a fuel. Meanwhile, the dehydration reaction occurred as well. It was observed that a spark appeared at one corner then spread throughout the mass and yielded voluminous solid product. Here, the precursor solutions with $0: 1,1: 30,1: 24,1: 20$ and $1: 10$ molar ratios of $\mathrm{In}^{3+}: \mathrm{Zn}^{2+}$ were prepared and the corresponding solid products S0, S1, S2, S3, S4 and S5 were obtained, respectively.

The phase structure and phase purity of the obtained samples were examined by X-ray diffraction (XRD; X'pert, Philips, Holland) with $\mathrm{Cu} \mathrm{K} \mathrm{K}_{\alpha 1}$ radiation $(\lambda=1.5406 \AA)$. The morphology of the obtained samples were investigated using field emission scanning electronic microscopy (FE-SEM; JSM6701F, JEOL, Japan) and transmission electron microscopy (TEM; JEM-3010, Questar, New Hope, USA).

Fig. 1a is a schematic of the gas sensor device and the basic fabrication process is as our previously studies. ${ }^{17} \mathrm{In}$ brief, the assynthesized porous $\operatorname{In}_{2} \mathrm{O}_{3} / \mathrm{ZnO}$ heterostructures were mixed and grinded with adhesive in an agate mortar to form a paste. The paste used as sensitive body was coated on an alumina tube with $\mathrm{Au}$ electrodes and platinum wires. A Ni-Cr alloy crossing alumina tube was used as a heating resistor which ensured both substrate heating and temperature controlling. Each element was sintered at $500{ }^{\circ} \mathrm{C}$ for $2 \mathrm{~h}$ in air. In order to improve their stability and repeatability, the gas sensors were aged at $300{ }^{\circ} \mathrm{C}$ for 10 days in air. The gas sensing performances were measured by HW-30A gas sensing measurement system (Hanwei Ltd., Zhengzhou, China), as shown in Fig. 1b, which has a glass test chamber of $15 \mathrm{~L}$. When $\mathrm{Cl}_{2}$ gas was injected to the chamber from a little hole in the chamber wall, the resistance of the sensor began changing. The concentration of the test gas was controlled by the amount of the pure gas injected. $I-V$ characteristics of the sensors were investigated by a Keithley sourcemeter (Model 2410, Cleveland, USA) which was connected with the gas sensing measurement system in the voltage range from $-20 \mathrm{~V}$ to $20 \mathrm{~V}$. Sensitivity is defined as the ratio of $R_{\text {gas }} / R_{\text {air }}$, where $R_{\text {air }}$ and $R_{\text {gas }}$ are the resistance values measured in air and in $\mathrm{Cl}_{2}$ gas, respectively. The response/recovery time is defined as

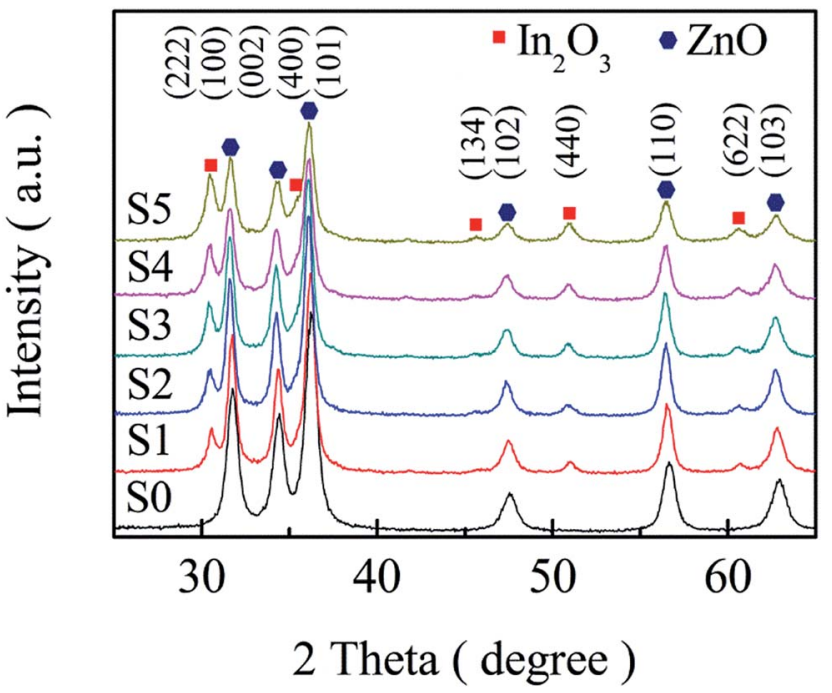

Fig. 2 XRD patterns of different heterostructures.

the time taken to achieve $90 \%$ of the final change in resistance following the change of gas concentration.

\section{Results and discussion}

Fig. 2 displays the powder XRD patterns, two sets of diffraction peaks mixed together can be observed from the spectra, which can be indexed to hexagonal wurtzite ZnO (JCPDS no. 36-1451) and body-centred-cubic $\operatorname{In}_{2} \mathrm{O}_{3}$ (JCPDS no. 65-3170). There are no other characteristic peaks and peak shift detected, indicating that high purity and good crystalline $\mathrm{In}_{2} \mathrm{O}_{3}$ and $\mathrm{ZnO}$ are formed. Moreover, the relative intensity of $\operatorname{In}_{2} \mathrm{O}_{3}$ diffraction peaks increases as the molar ratio of $\mathrm{In}^{3+}: \mathrm{Zn}^{2+}$ increasing in the precursor solutions. The average crystallite sizes of all samples can be estimated by the Debye-Scherrer formula and the results are S0, S1, S2, S3, S4 and S5 are $13.21 \mathrm{~nm}(\mathrm{~S} 0), 14.70 \mathrm{~nm}(\mathrm{~S} 1)$, $13.90 \mathrm{~nm}(\mathrm{~S} 2), 13.76 \mathrm{~nm}(\mathrm{~S} 3), 13.31 \mathrm{~nm}(\mathrm{~S} 4)$ and 11.64(S5) nm, respectively.

Fig. 3 shows the SEM images of different heterostructures. In Fig. 3a, pure $\mathrm{ZnO}$ shows self-assembly of three-dimensional porous rods with quite uniform size, the length and width of the rods are $1-2 \mu \mathrm{m}$ and $100-200 \mathrm{~nm}$, respectively. After the introduction of $\operatorname{In}_{2} \mathrm{O}_{3}$ the morphologies of the rods begin changing. At first, as the amount of $\mathrm{In}_{2} \mathrm{O}_{3}$ increases the rod length become shorter (Fig. $3 \mathrm{~b}$ and $\mathrm{c}$ ), further increases the

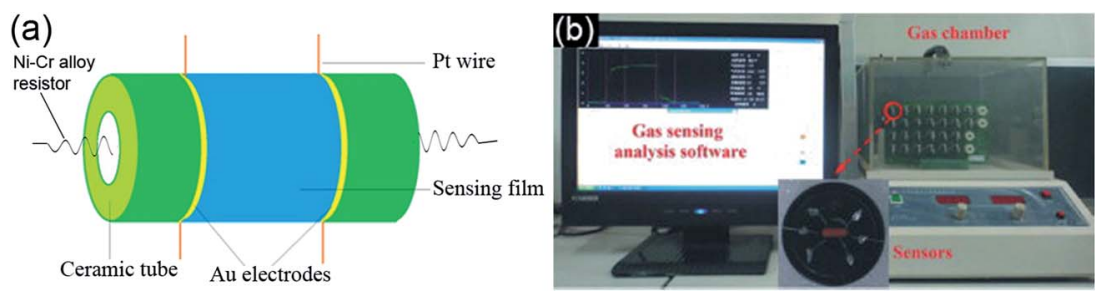

Fig. 1 (a) Schematic structure of the gas sensor and (b) gas-sensing measurement system (inset: sensor fabricated using $\mathrm{In}_{2} \mathrm{O}_{3} / \mathrm{ZnO}$ heterostructures). 

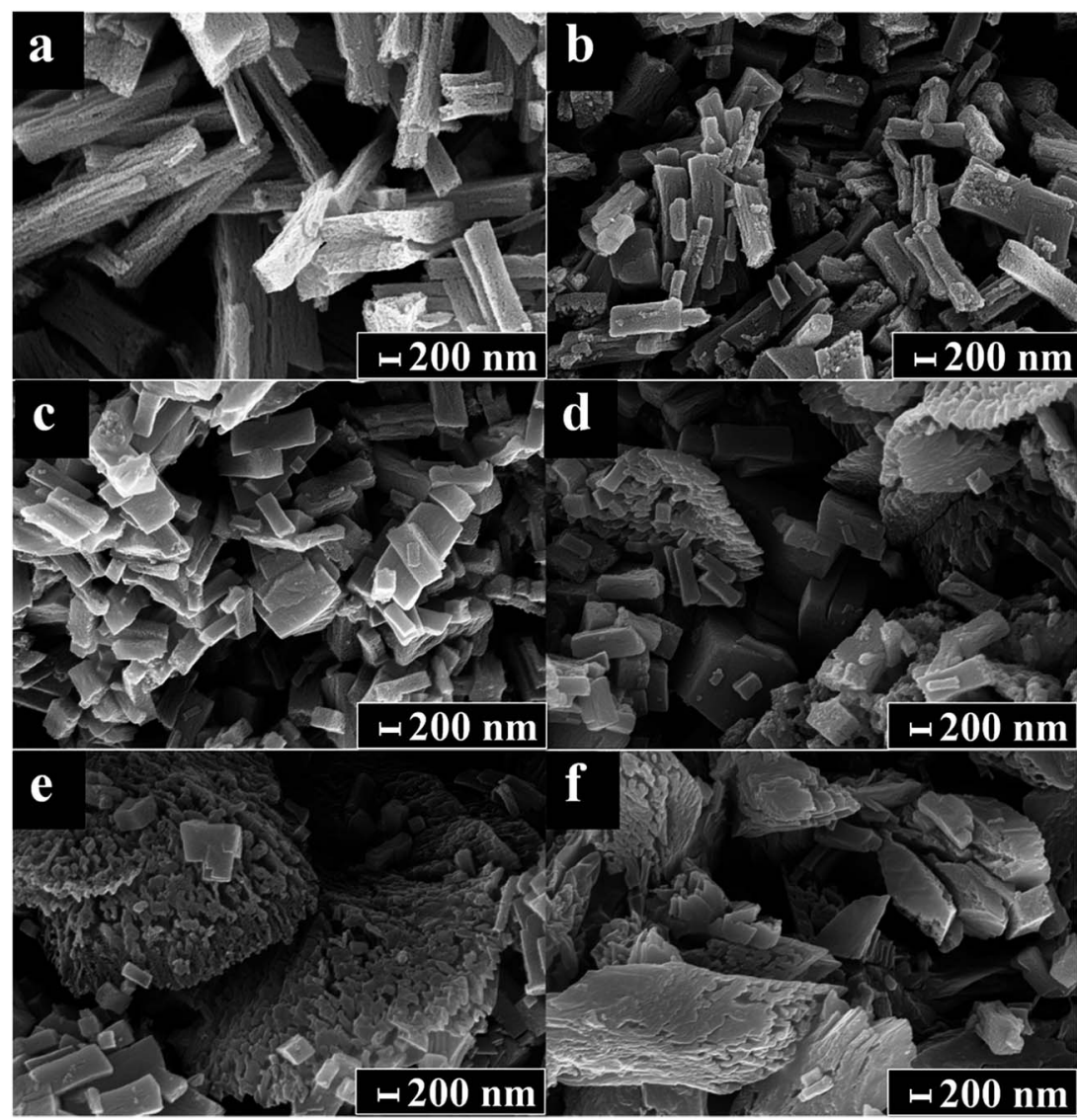

Fig. 3 SEM images of SO (a), S1 (b), S2 (c), S3 (d), S4 (e) and S5 (f).

amount of $\operatorname{In}_{2} \mathrm{O}_{3}$ the long structures gradually transform into random structures - irregular porous agglomerates of nanoheterostructures (Fig. 3d-f).

Fig. 4 shows the typical TEM analysis results of the heterostructures. The low magnification TEM image (Fig. 4a) demonstrates that the heterostructures possess a porous structure. The HRTEM image (Fig. 4b) indicates the heterostructures are composed of a large amount of nano-crystallites. Moreover, two sets of lattice fringes can be observed, the lattice distances of $0.282 \mathrm{~nm}$ and $0.253 \mathrm{~nm}$ match the (100) reflection of $\mathrm{ZnO}$ and the (400) reflection of cubic $\operatorname{In}_{2} \mathrm{O}_{3}$, respectively. The electron energy disperse spectroscopy (EDS) analysis result (Fig. 4c) shows that only Zn, In and O elements can be detected.

In addition, the selected area electron diffraction (SAED) pattern (Fig. 4d) demonstrates clear rings with superimposed bright spots. The SAED pattern rings can be indexed as the (100), (002) reflections of $\mathrm{ZnO}$ and the (211), (222) reflections of $\mathrm{In}_{2} \mathrm{O}_{3}$, which is in agreement with the XRD patterns. These results further confirm the nano-crystalline nature of the $\operatorname{In}_{2} \mathrm{O}_{3} /$ $\mathrm{ZnO}$ heterostructures.

Fig. 5 shows the $I-V$ curves of different sensors exposed to air and $50 \mathrm{ppm} \mathrm{Cl}_{2}$ at $300^{\circ} \mathrm{C}$. All the $I-V$ curves are close to linear in low voltage region and fairly symmetric between positive and negative values of the voltage, which indicates all the sensors have good ohmic behaviors. Normally a good ohmic behavior means a high gas sensitivity. ${ }^{18}$ The sensor based on S2 has the maximum slop (resistance) variation which means it has the maximum gas sensitivity. Inset I of Fig. 6a shows the gas sensitivities of the sensors based on the heterostructures when exposed to $50 \mathrm{ppm} \mathrm{Cl}_{2}$ at $370{ }^{\circ} \mathrm{C}$. The sensitivity is calculated as to the slop (resistance) variations of the related $I-V$ curves in
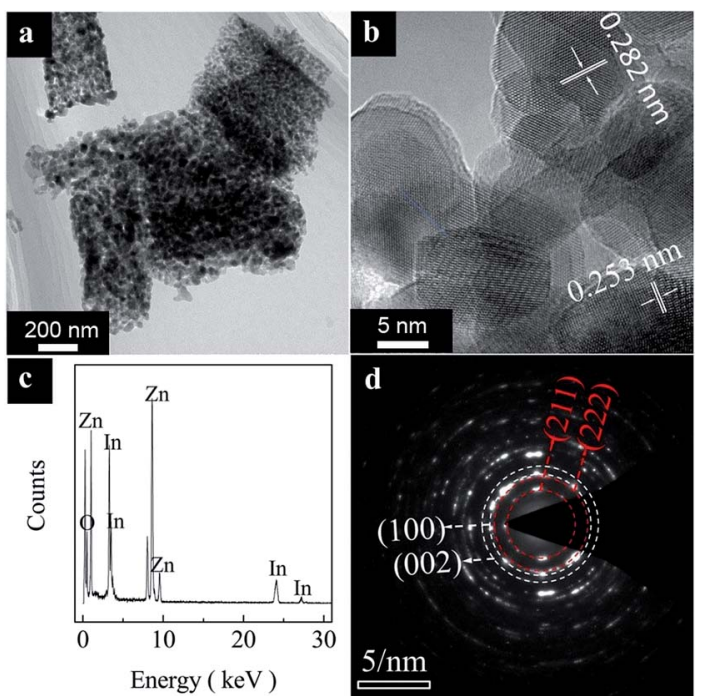

Fig. 4 Typical TEM image (a), HRTEM image (b), EDS analysis result (c) and SAED pattern (d) of the heterostructures. 


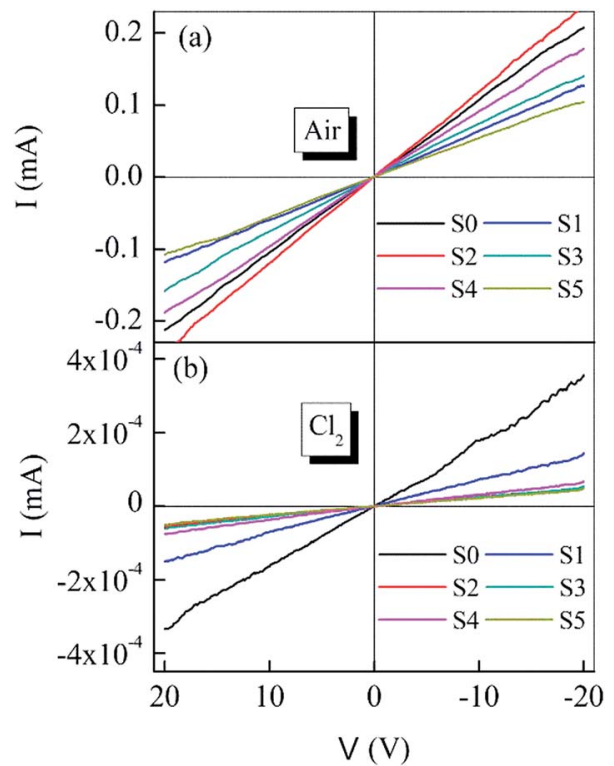

Fig. $51 / V$ characteristics of different sensors exposed to air and $50 \mathrm{ppm} \mathrm{Cl}_{2}$.

Fig. 5. Inset II of Fig. 6a shows the sensitivity transitions of S2 sensor depending on the temperature when exposed to $50 \mathrm{ppm}$ $\mathrm{Cl}_{2}$. The sensitivity increases as temperature increasing and reaches the maximum value at $370{ }^{\circ} \mathrm{C}$. These results indicate that S2 exhibits the maximum sensitivity and the optimum operating temperature for all the heterostructure sensors is determined to be $370{ }^{\circ} \mathrm{C}$.

Fig. 6a displays the sensitivity changes of $\mathrm{S} 2$ when exposed to $\mathrm{Cl}_{2}$ with the concentrations of $1,5,10,20,50$ and $100 \mathrm{ppm}$ at $370{ }^{\circ} \mathrm{C}$. It indicates that the sensitivity increases as $\mathrm{Cl}_{2}$ concentration increasing and can reach a huge value of 6610 when exposed to $50 \mathrm{ppm} \mathrm{Cl}_{2}$. Fig. 6b shows the typical response and recovery curve of $\mathrm{S} 2$ when exposed to $50 \mathrm{ppm}_{2}$. It can be observed that the response and recovery time are approximate $8 \mathrm{~s}$ and $6 \mathrm{~s}$, respectively, which are acceptable in practical application. Fig. $6 \mathrm{c}$ displays the stability of the sensor based on $\mathrm{S} 2$ toward $50 \mathrm{ppm} \mathrm{Cl}_{2}$ at $370^{\circ} \mathrm{C}$. The results indicate that the gas response decreases over time. But the decrease is not very big which is reduced only by $\sim 14 \%$ after 15 days went by, and the response is stable at $\sim 5700$ after 9 days.

Finally, the comparison with other reported sensing materials toward $\mathrm{Cl}_{2}$ shown in Table $1 .^{13,19-21}$ Sensing performance of $\mathrm{In}_{2} \mathrm{O}_{3} / \mathrm{ZnO}$ is significantly superior to those previously reported.

For metal oxide gas sensors, the change of resistance is mainly caused by the adsorption and desorption of gas molecules on the surface of the sensing structure. In the air oxygen species are adsorbed on the surface of particles, and then were ionized into $\mathrm{O}^{-}$(ads) or $\mathrm{O}^{2-}$ (ads) by capturing free electrons from the valence band of the metal oxide leading to the formation of thick space charge layer. ${ }^{17,19}$ Upon exposure to $\mathrm{Cl}_{2}$ which is a stronger oxidizer than oxygen, $\mathrm{Cl}_{2}$ can not only capture the electrons from the valence band due to its higher electrophilic properties but also react with the pre-adsorbed oxygen species leading to the formation of $\mathrm{Cl}_{2}$ species
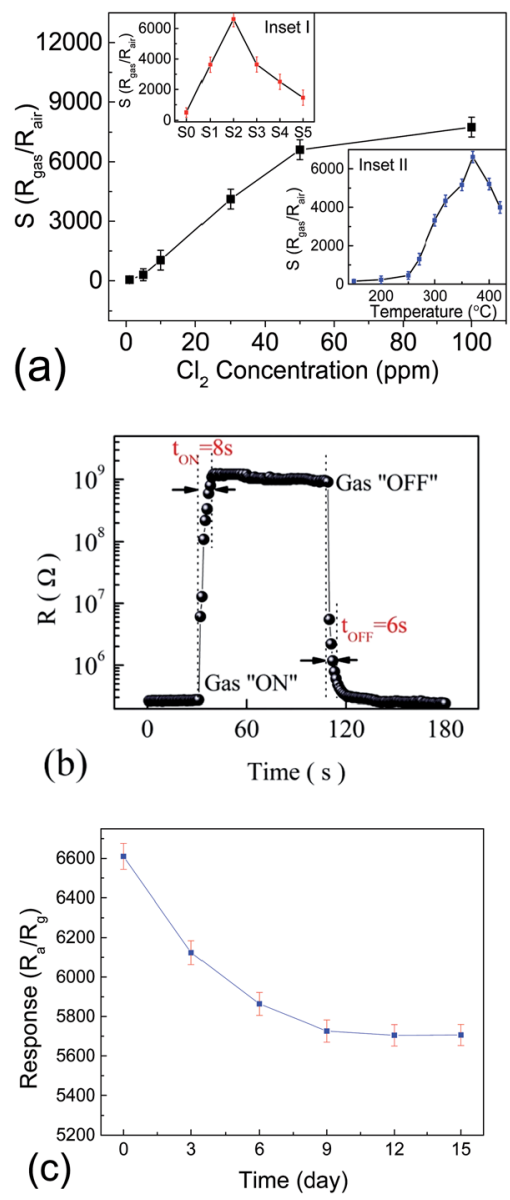

Fig. 6 (a) Sensitivities of the sensors based on $\mathrm{S} 2$ exposed to $\mathrm{Cl}_{2}$ with the concentrations of $1,5,10,30,50$ and $100 \mathrm{ppm}$ at $370^{\circ} \mathrm{C}$. Inset I shows the sensitivities of different sensors exposed to $50 \mathrm{ppm} \mathrm{Cl}_{2}$. Inset II shows the sensitivities of the sensors based on S2 exposed to $50 \mathrm{ppm} \mathrm{Cl} \mathrm{Cl}_{2}$ at different temperatures. (b) Response and recovery curve of the gas sensor based on $\mathrm{S} 2$ exposed to $50 \mathrm{ppm} \mathrm{Cl}_{2}$ at $370{ }^{\circ} \mathrm{C}$. (c) Stability of the sensor based on $\mathrm{S} 2$ toward $50 \mathrm{ppm} \mathrm{Cl}_{2}$ at $370{ }^{\circ} \mathrm{C}$. The error bars mean the standard deviation between the three times in the gas sensing testing of all the three sensors made by the same fabricated process.

$\left(\mathrm{Cl}^{-}\right.$(ads) or $\left.\mathrm{Cl}^{-} \mathrm{o}\right) \cdot{ }^{19} \mathrm{ZnO}$ and $\mathrm{In}_{2} \mathrm{O}_{3}$ are n-type semiconductors, when they are exposed to $\mathrm{Cl}_{2}$ the resistance increases for the charge carriers decreasing.

On the basis of the above results, it can be suggested that $\mathrm{In}_{2} \mathrm{O}_{3} / \mathrm{ZnO}$ heterostructures show an enhanced gas sensing performance compared with pure $\mathrm{ZnO}$, and an appropriate amount of $\operatorname{In}_{2} \mathrm{O}_{3}$ can largely improve the sensitivity of $\operatorname{In}_{2} \mathrm{O}_{3}$ / $\mathrm{ZnO}$ heterostructures while the excess of $\operatorname{In}_{2} \mathrm{O}_{3}$ plays the opposite role. Several reasons are believed to be responsible for this. As shown in the TEM (Fig. 4) image, a large amount of $\mathrm{ZnO}$ and $\mathrm{In}_{2} \mathrm{O}_{3}$ nanoparticles are piled up to form the loose and porous heterostructures. The BET surface area analysis results are shown in Table S1 and Fig. S1 in ESI, $\uparrow$ which confirm the $\mathrm{In}_{2} \mathrm{O}_{3} / \mathrm{ZnO}$ heterostructures have porous structures and large specific surface areas more than $30 \mathrm{~m}^{2} \mathrm{~g}^{-1}$. A loose and porous structure can provide a higher surface area to volume ratio which benefits the adsorption and diffusion processes of $\mathrm{NO}_{2}$ 
Table $1 \mathrm{Cl}_{2}$ sensing performance of $\mathrm{In}_{2} \mathrm{O}_{3} / \mathrm{ZnO}$ and comparison with other reported sensing materials

\begin{tabular}{|c|c|c|c|c|c|}
\hline Chemical compounds & $\begin{array}{l}\text { Concentration } \\
\left(\mathrm{Cl}_{2}\right)\end{array}$ & Response & $\begin{array}{l}t \text { (response) } / t \text { (recovery) } \\
\text { (s) }\end{array}$ & $\begin{array}{l}\text { Operating temperature } \\
\left({ }^{\circ} \mathrm{C}\right)\end{array}$ & Morphology \\
\hline $\mathrm{In}_{2} \mathrm{O}_{3} / \mathrm{ZnO}$ (this work) & $50 \mathrm{ppm}$ & 6610 & $8 / 6$ & 370 & Nanoparticles \\
\hline $\mathrm{In}_{2} \mathrm{O}_{3} / \mathrm{SnO}_{2}$ (ref. 13) & $50 \mathrm{ppm}$ & 1034.3 & $2 / 9$ & 260 & Nanoparticles \\
\hline $\mathrm{In}_{2} \mathrm{O}_{3}$ (ref. 20) & $50 \mathrm{ppm}$ & 945.6 & $2 / 8$ & 260 & Nanoparticles \\
\hline $\mathrm{ZnO}^{21}$ & $5 \mathrm{ppm}$ & 199 & $8 / 50$ & 200 & Nanoparticles \\
\hline
\end{tabular}

gas resulting in the improvement of the gas sensing properties. $^{22-24}$ Moreover, small sized particles enhanced the gas sensing activity to a great extent. A small particle size allows the electrons to reach the surface easily and hence enhances the gas sensing performance. ${ }^{25,26}$ In addition, the formation of a nanoheterostructure between $\operatorname{In}_{2} \mathrm{O}_{3}$ and $\mathrm{ZnO}$ is known to increase the gas response and selectivity. ${ }^{27,28}$ Just after the formation of junction between $\operatorname{In}_{2} \mathrm{O}_{3}$ and $\mathrm{ZnO}$, the electrons will flow from the material with low work function to that with high work function until their Fermi levels equalize, which creates an electron depletion layer at the interface and bends the energy band. Unfortunately, the relative levels of work functions for $\mathrm{In}_{2} \mathrm{O}_{3}$ and $\mathrm{ZnO}$ are not consistent in the literatures and depend on the degree of nonstoichoiometry. ${ }^{29-31}$ In any case, the formation of electron depletion layer in the vicinity of the interface due to the difference of work functions can be considered, which increases the adsorption of oxygen species. ${ }^{12}$ On the other hand, as shown in Fig. 4, the excessive $\operatorname{In}_{2} \mathrm{O}_{3}$ leads to an agglomerate structure, which decreases the number of the active sites on the surface of $\mathrm{ZnO}$. Correspondingly, the number of oxygen ions chemisorbing will be reduced, resulting in the decrease of the gas response. ${ }^{28}$

In practical application, selectivity is an important parameter for gas sensors to distinguish different kinds of detected gases. Fig. 7 shows the sensitivities of porous $\operatorname{In}_{2} \mathrm{O}_{3} / \mathrm{ZnO}$

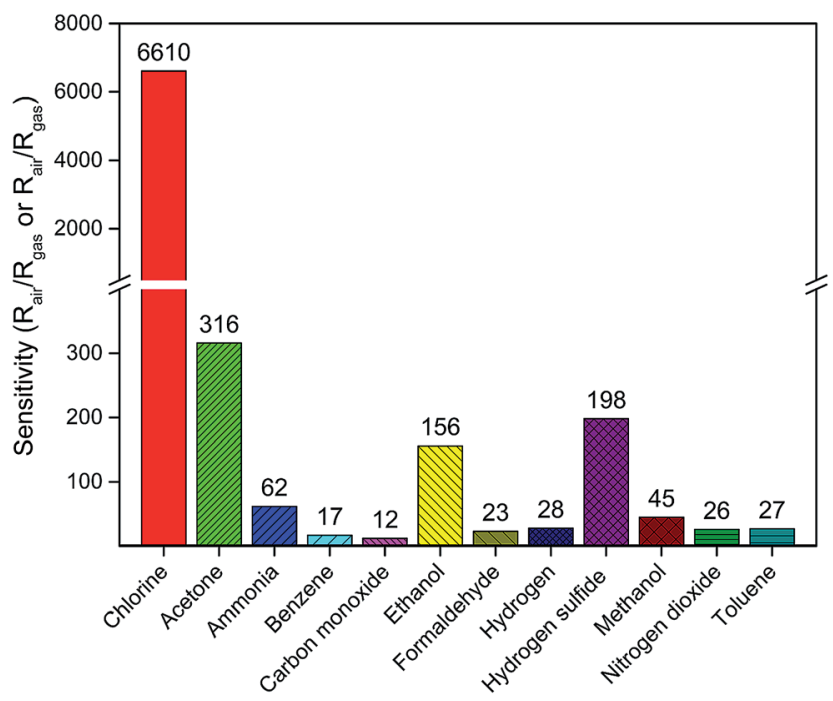

Fig. 7 Sensitivity of $\ln _{2} \mathrm{O}_{3} / \mathrm{ZnO}$ heterostructures upon exposure to $50 \mathrm{ppm}$ of different gases at $370{ }^{\circ} \mathrm{C}$. heterostructures sensor (S2) against chlorine, benzene, toluene, hydrogen, carbon monoxide, nitrogen dioxide, ammonia, ethanol, methanol, formaldehyde, and acetone gases (the concentrations of these test gases are all $50 \mathrm{ppm}$ at $370{ }^{\circ} \mathrm{C}$. If the resistance of the sensor in test gas is smaller than in air, the sensitivity is defined as the ratio of $\left.R_{\text {air }} / R_{\text {gas }}\right)$. It can be observed from Fig. 7 that the porous $\operatorname{In}_{2} \mathrm{O}_{3} / \mathrm{ZnO}$ heterostructures sensor possesses a far higher selectivity to $\mathrm{Cl}_{2}$ than the other gases. The different sensitivities under the same condition can be attributed to different gases possess different inherent energies level for adsorption, desorption and reaction with active sites on the surface of the sensing materials. ${ }^{32}$

\section{Conclusions}

Self-assembled porous $\operatorname{In}_{2} \mathrm{O}_{3} / \mathrm{ZnO}$ heterostructures are successfully synthesized via a low temperature solution combustion method. The gas sensor based on the porous $\operatorname{In}_{2} \mathrm{O}_{3} /$ $\mathrm{ZnO}$ heterostructures exhibits highly improved sensitivity to dilute chlorine. The sensitivity value increases linearly with the increasing $\mathrm{Cl}_{2}$ concentration and reaches 6610 exposed to $50 \mathrm{ppm} \mathrm{Cl}_{2}$ at $370{ }^{\circ} \mathrm{C}$. Moreover, the response and recovery time are approximate $8 \mathrm{~s}$ and $6 \mathrm{~s}$, respectively. The enhanced gas sensing performance are attributed to the small particle size, loose and porous structure and the formation of a depleted electron depletion layer at $\operatorname{In}_{2} \mathrm{O}_{3}-\mathrm{ZnO}$ interface.

\section{Acknowledgements}

This work was supported by the Doctoral Scientific Research Foundation of Taiyuan University of Science and Technology (No. 20162006), Scientific and Technological Innovation Programs of Higher Education Institutions in Shanxi (2016-59), Talents Training Project of Shanxi Graduate Joint Training Base (2016-37), Shanxi Province Science Foundation and Fund for Shanxi Key Subjects Construction (201601D102019).

\section{References}

1 W. Hui, X. Jiaqiang and P. Qingyi, CrystEngComm, 2010, 12, 1280.

2 P. Van Tong, N. D. Hoa, N. Van Duy and N. Van Hieu, $R S C$ Adv., 2015, 5, 25204.

3 V. B. Kamble and A. M. Umarji, J. Mater. Chem. C, 2013, 1, 8167. 
4 P. Li, H. Fan, Y. Cai and M. Xu, CrystEngComm, 2014, 16, 2715.

5 A. L. Hunt and J. F. Alder, Anal. Commun., 1996, 33, 61.

6 H. Zhang, J. Li, H. Zhang, X. Liang, C. Yin, Q. Diao, J. Zheng and G. Lu, Sens. Actuators, B, 2013, 180, 66.

7 A. Abdelhalim, M. Winkler, F. Loghin, C. Zeiser, P. Lugli and A. Abdellah, Sens. Actuators, B, 2015, 220, 1288.

8 G. F. Fine, L. M. Cavanagh, A. Afonja and R. Binions, Sensors, 2010, 10, 5469.

9 N. D. Hoa, V. V. Quang, D. Kim and N. V. Hieu, J. Alloys Compd., 2013, 549, 260.

10 L. Ma, H. Fan, H. Tian, J. Fang and X. Qian, Sens. Actuators, B, 2016, 222, 508.

11 J. Tamaki, C. Naruo, Y. Yamamoto and M. Matsuoka, Sens. Actuators, B, 2002, 83, 190.

12 S. Wang, Z. Li, P. Wang, C. Xiao, R. Zhao, B. Xiao, T. Yang and M. Zhang, CrystEngComm, 2014, 16, 5716.

13 P. Li, H. Fan and Y. Cai, Sens. Actuators, B, 2013, 185, 110. 14 H. Tian, H. Fan, M. Li and L. Ma, ACS Sens., 2016, 1, 243.

15 F.-T. Li, J. Ran, M. Jaroniec and S. Z. Qiao, Nanoscale, 2015, 7, 17590.

16 W. Wen and J.-M. Wu, RSC Adv., 2014, 4, 58090.

17 X. Zou, H. Fan, Y. Tian, M. Zhang and X. Yan, Dalton Trans. 2015, 44, 7811.

18 J. S. Yang, J. H. Park, S.-I. Kim, Y. T. Kim and Y. H. Kim, Curr. Appl. Phys., 2010, 10, 370.
19 X.-B. Wang, N. Qin, T.-J. Lou and X.-D. Lou, Phys. B, 2011, 406, 597.

20 P. Li, H. Fan and Y. Cai, Colloids Surf., A, 2014, 453, 109.

21 S. T. Navale, V. V. Jadhav, K. K. Tehare, R. U. R. Sagar, C. S. Biswas, M. Galluzzi, W. Liang, V. B. Patil, R. S. Mane and F. J. Stadler, Sens. Actuators, B, 2017, 238, 1102.

22 P. Song, Q. Wang and Z. Yang, Mater. Lett., 2011, 65, 430.

23 G. Korotcenkov and B. K. Cho, Sens. Actuators, B, 2017, 244, 182.

24 P. Li and H. Fan, Mater. Sci. Semicond. Process., 2015, 29, 83.

25 N. Vorobyeva, M. Rumyantseva, D. Filatova, E. Konstantinova, D. Grishina, A. Abakumov, S. Turner and A. Gaskov, Sens. Actuators, B, 2013, 182, 555.

26 J.-A. Park, J. Moon, S.-J. Lee, S. H. Kim, H. Y. Chu and T. Zyung, Sens. Actuators, B, 2010, 145, 592.

27 M. Gholami, A. A. Khodadadi, A. Anaraki Firooz and Y. Mortazavi, Sens. Actuators, B, 2015, 212, 395.

28 L. Han, D. Wang, J. Cui, L. Chen, T. Jiang and Y. Lin, J. Mater. Chem., 2012, 22, 12915.

29 S. Martha, K. H. Reddy and K. M. Parida, J. Mater. Chem. A, 2014, 2, 3621.

30 W. Zang, Y. Nie, D. Zhu, P. Deng, L. Xing and X. Xue, J. Phys. Chem. C, 2014, 118, 9209.

31 Z. Wang, B. Huang, Y. Dai, X. Qin, X. Zhang, P. Wang, H. Liu and J. Yu, J. Phys. Chem. C, 2009, 113, 4612.

32 X. Chi, C. Liu, Y. Li, H. Li, L. Liu, X. Bo, L. Liu and C. Su, Mater. Sci. Semicond. Process., 2014, 27, 494. 